\title{
Comunidade Porvir: Emancipação Social e Configurações Comunitárias em um Ponto de Cultura
}

\author{
Adolfo Pizzinato ${ }^{1}$ \\ Pedro de Castro Tedesco ${ }^{2}$ \\ ${ }^{1}$ Universidade Federal do Rio Grande do Sul, RS, Brasil. $\quad{ }^{2}$ Universidade Federal de Santa Catarina, SC, Brasil. \\ João Pedro Cé ${ }^{3}$ \\ ${ }^{3}$ Pontifícia Universidade Católica, RS, Brasil.
}

\begin{abstract}
Resumo: O presente artigo trata das implicações decorrentes da atual sistematização das políticas culturais brasileiras, em especial na interface entre Arte, Cultura e possibilidades de emancipação social e ação política. A pesquisa, desenvolvida junto a um Ponto de Cultura localizado em um bairro da zona sul de Porto Alegre/RS, teve como aporte metodológico a etnografia de um dos autores do artigo durante o período de 2013-2014. Como aporte teórico utilizado nas discussões e resultados, a utilização da filosofia de Jacques Rancière e suas considerações em relação a configurações de comunidade política e formas de pensamento em Arte foram utilizadas. No período de um ano, foi possível observar que as políticas culturais brasileiras, devido a sua formatação e execução, acabam por tornar difusas as atribuições concernentes ao Estado e a participação de empresas privadas na área artística cultural; não só, ainda que a atual orientação das políticas culturais deem ensejo a ampliação, representatividade e legitimação de produções culturais não majoritárias, a emancipação social e ação política desses contingentes populacionais não decorre, necessariamente, desse conjunto de ações. Salienta-se, portanto, a imprescindível participação dos atores sociais visados pelas políticas culturais para que as possibilidades de emancipação social se concretizem.
\end{abstract}

Palavras-chave: Políticas Públicas, Arte, Comunidade, Cultura, Psicologia Política.

\section{Possible Communities: Social Emancipation and Communitarian Arrangements in a Ponto de Cultura}

\begin{abstract}
The present work deals with the organizational framework of Brazilian cultural policies, especially in the interface between Art, Culture, possibilities of social emancipation and political action. The research, developed in a Culture Point located in a neighborhood in the southern zone of Porto Alegre/RS, had as methodological orientation an ethnography realized by one of the authors of the article during the period of 2013-2014. As a theoretical contribution used in the discussions and results, the philosophy of Jacques Rancière and its considerations in relation to political community configurations and art forms of thought were used. During one year, it was possible to realize that Brazilian cultural policies, due to their formatting and execution, end up making diffuse the attributions concerning the Brazilian State and the participation of private companies in the Art and Culture area. Also, although the current orientation of cultural policies give chance to an enlargement, representativeness and legitimation of non major cultural productions, the social emancipation and political action of these population does not necessarily follow from this set of actions. Therefore, it is necessary to emphasize the indispensable participation of the social actors targeted by the cultural policies so that the possibilities of social emancipation become concrete.
\end{abstract}

Keywords: Public Politics, Art, Community, Culture, Political Psychology. 


\title{
Comunidad Porvenir: Emancipación Social y Configuraciones Comunitarias en un Punto de Cultura
}

\begin{abstract}
Resumen: El presente artículo trata de las implicaciones derivadas de la actual sistematización de las políticas culturales brasileñas, en especial en la interfaz entre Arte, Cultura y posibilidades de emancipación social y acción política. La investigación, desarrollada junto a un Punto de Cultura ubicado en un barrio de la zona sur de Porto Alegre / RS, tuvo como aporte metodológico la etnografía de uno de los autores del artículo durante el período de 2013-2014. Como aporte teórico utilizado en las discusiones y resultados, la utilización de la filosofía de Jacques Rancière y sus consideraciones en relación a configuraciones de comunidad política y formas de pensamiento en Arte fueron utilizadas. En el período de 1 año, fue posible observar que las políticas culturales brasileñas, debido a su formateo y ejecución, acaban por hacer difusas las atribuciones concernientes al Estado y la participación de empresas privadas en el área artística cultural; no sólo, aunque la actual orientación de las políticas culturales de la ampliación, representatividad y legitimación de producciones culturales no mayoritarias, la emancipación social y acción política de esos contingentes poblacionales no deriva necesariamente de ese conjunto de acciones. Se subraya, por lo tanto, la imprescindible participación de los actores sociales a las políticas culturales para que las posibilidades de emancipación social se concreten.
\end{abstract}

Palabras clave: Políticas Públicas, Arte, Comunidad, Cultura, Psicología Política.

\section{Introdução}

As políticas culturais brasileiras são articuladas e concebidas, desde as décadas de 1980-1990, por meio de editais e seleção de projetos cujo financiamento, de cunho público-privado, é orientado e concretizado por meio da avaliação desses projetos enviados ao Ministério da Cultura (MinC). As atividades culturais abarcadas pelos editais variam desde eventos festivos e shows de bandas populares a programas de amplo alcance midiático como o "Criança Esperança"; isso ocorre, sobretudo, tanto pelo pouco orçamento disponibilizado à área de cultura, quanto pelo MinC prescindir de uma formação teórica sólida em relação ao conceito de "cultura" por ele empregado (Silva, \& Dutra, 2011). Nesse particular, o conceito de "cultura" utilizado atualmente pelo MinC é associado à política transnacional da Organização das Nações Unidas para a Educação, a Ciência e a Cultura (Unesco), compreendendo "cultura" como uma forma de inserção econômica e de desenvolvimento social (Brasil, 2005; UNESCO, 2005) - dando margem a monetização das políticas públicas culturais e seleção de parcelas populacionais compreendidas como "rentáveis" aos investimentos na área artística e cultural (Feltran, 2014).
Nesse contexto, um dos principais diferenciais em relação à política de financiamento cultural no início dos anos 2000 reside no direcionamento dos investimentos e financiamento previstos pelo Ministério da Cultura. Em 2004, é criado o Programa Nacional de Cultura, Educação e Cidadania - Cultura Viva pelo ministro Gilberto Gil (2003-2008), o qual traz como eixos de ações os Pontos de Cultura, Pontões de Cultura, Ação Griô, Pontinhos de Cultura, Ponto de Mídia Livre, o prêmio Taxaua, os Agentes de Cultura Livre e a Cultura Digital (Brasil, 2005). Esse conjunto de ações figura como um desdobramento do novo foco das políticas culturais brasileiras, o qual passa a ser as populações de baixa renda, adolescentes e adultos em situação de vulnerabilidade social, estudantes da rede básica do ensino público, comunidades indígenas e quilombolas e agentes culturais e coletivos de artistas (Brasil, 2005).

Em 2014, a Lei no 13.018 institui a Política Nacional de Cultura Viva, na qual as ações anteriores previstas pelo programa são formalizadas e orientadas como diretriz do país em assuntos envolvendo manifestações culturais. A Política Nacional de Cultura Viva, por um lado se constitui como uma ação a qual tem por iniciativa uma valorização de atividades culturais comprometidas tanto com a cultura local de 
suas comunidades, quanto com manifestações culturais de matriz africana e indígena. Por outro lado, a isenção fiscal para empresas que financiassem projetos culturais foi mantida, o que gerou desdobramentos e associações nas atuais políticas culturais brasileiras a áreas como gestão de territórios urbanos, trabalho informal e políticas de saúde (Rizek, 2013). Nesse ponto, observa-se que a partir da gestão Temer (2016-atual) houve mudanças consideráveis no MinC, das quais destaca-se: quatro ministros da Cultura em menos de um ano de gestão e a extinção do Ministério da Cultura e sua consequente reversão após manifestações da comunidade acadêmica, classe artística e setores da sociedade civil.

Neste cenário de incrementada precarização, o programa dos Pontos de Cultura sobrevive por intermédio de entidades da sociedade civil, em geral, as Organizações da Sociedade Civil de Interesse Público (OSCIP), título jurídico conferido a Organizações Não Governamentais de caráter privado. As OSCIP, regulamentadas desde o início dos anos 2000, são organizações da sociedade civil que estabelecem regimes jurídicos de parcerias voluntárias com o Estado brasileiro, aliadas a promoção da assistência social, educação, saúde e cultura. Neste particular, em interface com as gestões federais, estaduais e municipais, as OSCIP podem disputar os editais provenientes do Ministério da Cultura, de modo que podem passar a viabilizar os Pontos de Cultura por meio de um convênio com o Poder Público.

É nesse cenário que este artigo pretende apresentar uma discussão sobre as Políticas Públicas de Cultura no Brasil a partir da experiência etnográfica de um dos pesquisadores em um Ponto de Cultura da cidade de Porto Alegre/RS. Em especial, tem como objetivo uma discussão em relação às implicações da efetivação de uma política pública via organização privada e os desdobramentos sobre as práticas e significados das atividades culturais nas comunidades nas quais se insere.

Como aporte teórico eleito para a discussão, utilizaremos alguns conceitos da obra de Jacques Rancière, em especial no que se refere aos diferentes modos de pensamento e identificação de Arte e as experiências de comunidade política que essas pressupõem. Das relações entre formas de pensamento em Arte e experiência de comunidade se torna possível discutir distintas noções de emancipação social e os meios para sua efetivação. $\mathrm{O}$ autor conceitua três regimes de identificação em Arte que derivam de formas de ser-em-comum, nomeada por partilha do sensivel (Rancière, 2009). A partilha do sensivel é um conceito que indica diferentes modos de construção de realidade sensível orientado por noções de função, competência e capacidades definindo tempos e espaços diferentes para cada ator social. Assim, a partilha do sensivel institui esferas de experiência e modos de habitar uma comunidade comum. Esses modos de habitar o comum, bem como as maneiras de partilhar e de pertencer a uma comunidade são associadas a três maneiras de pensar Arte, conceituadas em três regimes de identificação: o regime ético, o regime representativo e o regime estético (Rancière, 2009).

No regime ético há uma seleção de imagens segundo seu teor pedagógico, ou seja, não há uma autonomização da Arte, mas sim o que pode ser representado e difundido enquanto imagem. A autonomia da Arte, o que a define e possibilita nomeá-la enquanto tal é viabilizada pelo regime representativo. Nesse, a noção de mimese, organizada por Aristóteles, exerce um filtro de inclusão de ofícios que possam representar essas imagens, apresentando com isso uma forma de experiência e relação com o sensível hierarquizada segundo temas, gêneros e ofícios os quais passam a mediar a experiência artística (Rancière, 2009). Essa forma de identificar Arte é contraposta pelo que Rancière denomina por regime estético da Arte. Estética, para o autor, não se constitui como um campo de teoria em relação à Arte ou de discussões em relação ao Belo e a beleza, mas se configura como um domínio da arte - tal como o domínio ético e representativo (Rancière, 2009; 2011). Essa forma de pensar Arte se constitui como uma supressão e suspensão das hierarquias e relações estabelecidas pelo regime representativo, reunindo na experiência sensível a identificação entre sentimentos, ações e pensamentos contraditórios (Rancière, 2011).

Disso decorrem diferentes esferas de experiência em comunidade, associadas a esses modos de pensamento. Se nos regimes ético/representativo há a pressuposição de comunidades consensuais, pelo regime estético haveria a possibilidade de uma nova comunidade assentada pelas propriedades contraditórias da estética: a comunidade dissensual (Rancière, 2011). Uma comunidade consensual implica, para o autor, uma comunidade na qual os conflitos oriundos do convívio, bem como a gestão dos negócios comuns comunitários ficam a cargo de atores sociais cujos 
cargos apresentem as capacidades e competências necessárias para a resolução e manejo desses conflitos. Em uma comunidade dissensual o jogo entre capacidades e competências é reconfigurado, estando essas disponíveis a qualquer um/a, de modo que as hierarquias entre os atores sociais para a gestão dos negócios comuns da comunidade são abolidas dando ensejo a uma nova relação sensível comunitária.

Desse nó entre comunidade política e maneiras de pensamento artístico, possíveis pelo regime estético, deriva três cenários possíveis, os quais tentam consensualmente lidar com o dissenso próprio à comunidade estética: por meio de uma identificação plena da comunidade à Arte, na qual essa se realizaria mediante sua supressão - como nos programas da Bauhaus ou nos grafites urbanos (1); um superinvestimento nas obras de arte, nas quais a potência dissensual, ao ser contida na obra adia a promessa de uma comunidade futura (2); ou a diluição de qualquer possibilidade de comunidade mediante noções de "tudo pode ser arte" e uso indiscriminado de qualquer objeto cujo valor de troca tenha sido esgotado (3).

Nesse sentido, a análise das políticas culturais brasileiras, seu direcionamento às comunidades periféricas e concepção de sujeito ao qual se orientam podem dar ensejo a constituição de uma produção cultural que seja consoante a uma comunidade dissensual. Isso se justifica pela possibilidade de inclusão e acesso a atores sociais, na produção cultural brasileira, que tem suas produções reiteradamente marginalizadas e/ou pouco valorizadas. Contudo, cabe compreender de que forma essa relação é efetivada em um contexto neoliberal e de mercantilização das políticas públicas brasileiras (Feltran, 2014; Lautier, 2014), bem como as formas de articulação entre essa produção cultural e emancipação social.

\section{Método}

Tendo como objetivo a discussão em relação às políticas culturais brasileiras na interface com as parcerias-público privadas e seus desdobramentos, o presente artigo parte da experiência de um dos pesquisadores junto a um Ponto de Cultura eleito por conveniência localizado na periferia de Porto Alegre/ RS no decurso de março de 2013 a março de 2014. A partir desses contatos iniciais - e durante o término da graduação do pesquisador - o vínculo com o Ponto de Cultura foi se consolidando. Durante a realização de estágio curricular obrigatório em Psicologia na área de Psicologia Comunitária, um dos pesquisadores autor do presente cadastrou o Ponto de Cultura junto ao Centro de Referência da Assistência Social do território e começou a frequentar o espaço como usuário do local. Devido a esse envolvimento prévio e posterior aceitação da coordenação do Ponto de Cultura para o desenvolvimento da pesquisa foi escolhida a etnografia como orientação teórico-metodológica mais adequada para alcançar os objetivos propostos.

A prática etnográfica lança mão de diferentes recursos para a construção do material a ser analisado, como: diários de campo, memorandos ou fotografias. A relação estabelecida pelo/a pesquisador/a com os/ as participantes, bem como o tempo destinado ao processo de pesquisa leva a questionar pressupostos tradicionais em pesquisa, em especial, a concepção de um espaço de intervenção pré-existente passível de ser explorado, investigado e desvelado (Peirano, 2014). Com isso, ressalta-se que o campo de intervenção e o material construído resultam de uma coparticipação entre pesquisador/a-participante.

A orientação e viés da construção do material a ser analisado teve como princípio a realização de uma pesquisa no cotidiano (Spink, 2007) do Ponto de Cultura, de modo que as relações e experiências do pesquisador junto aos/as participantes passaram por um constante processo de construção das problemáticas relevantes à pesquisa. Assim, a inserção do pesquisador em reuniões de planejamento do Ponto de Cultura, em atividades de captação de aúdio de registros audiovisuais da cultura negra, reformas estruturais na sede do local (como pintura e reboco de paredes) e manutenção da limpeza do espaço possibilitaram momentos de reflexão em relação as práticas que ocorriam no Ponto de Cultura. Dessa maneira, os sucessivos encontros e envolvimento no cotidiano do Ponto de Cultura permitiu a elaboração tanto teórica, quanto prática das teorias e metodologias empregadas. Essa orientação, consoante às noções discutidas por Peirano (2014), pressupõe a etnografia como uma atividade simultaneamente prática e teórica, permeada por constantes processos de pertencimento/estranhamento.

Após o fechamento das atividades de pesquisa junto ao Ponto de Cultura, organizou-se a apresentação dos resultados e sua consequente discussão por meio de diferentes seções articuladas entre si: a Implementação do Ponto de Cultura surgiu a partir dos questionamentos suscitados pelos encontros iniciais durante a vivência de estágio e pelas conexões, a época apa- 
rentes, entre a política cultural dos Pontos de Cultura e a gestão da presidência do Brasil durante o período de 2003-2016. A seção Trajetória de vida e Divisão no Trabalho surgiu a partir da motivação de compreender as trajetórias laborais e de vida dos/as coordenadores/ as, trabalhadores/as e usuários/as do Ponto de Cultura em interface com as políticas culturais. Por fim, a Militância figura como um eixo transversal que, de certa forma, possibilita tanto a existência dos Pontos, quanto a motivação para as atividades desenvolvidas no local. As seções não esgotam as possibilidades e invenções no cotidiano do Ponto, mas são aqui apresentadas com a intenção de apresentar um panorama de aspectos relevantes elencados pelo pesquisador.

\section{Implementação do Ponto de Cultura}

No que se refere à Implementação do Ponto de Cultura essa ocorre, inicialmente, a partir da concepção e entendimento do que seria um Ponto de Cultura - menos da sua viabilidade jurídica do que pela sua representatividade e significado; disso, decorrem as formas de atuação do Ponto de Cultura junto à comunidade no qual ele se insere no tocante a pautas, ações, eventos e possibilidades de experiência aos/as moradores/as do bairro. A seleção dos/as participantes para o Ponto de Cultura, assim, figura muito associada às concepções e usos do espaço, apresentando marcadores como gênero, raça, afinidade e militância como eixos norteadores para essa seleção. A sustentabilidade do local - seja o espaço físico, sejam os recursos humanos para o funcionamento do Ponto de Cultura - depende da submissão de projetos para disputa de editais e de negociações com organizações sociais e instâncias de âmbito municipal, estadual e federal via convênios.

A viabilização do Ponto de Cultura ocorre mediante a disputa de editais disponibilizados pelo Ministério da Cultura, o qual, por intermédio de repasses financeiros de diferentes instâncias federais, tem como objetivo desenvolver projetos artístico-culturais especialmente voltados à juventude em comunidades periféricas. Segundo a regulamentação jurídica do Programa Cultura Viva, haveria o envolvimento prévio da comunidade para a implementação do local, bem como de parceiros jurídicos eleitos pela comunidade que auxiliem a efetivação de um Ponto de Cultura. Dessa forma, após a escrita e redação de um projeto de Ponto de Cultura, a OSCIP ou Organização Não Governamental (ONG) que ganhe o edital passa a ser a representante jurídica do espaço, auxiliando-o no desenvolvimento de suas atividades e projetos. Nesse contexto, cabe problematizar e discutir a delicada relação entre as políticas públicas e Organizações da Sociedade Civil de Interesse Público. As OSCIP, mesmo caracterizadas como uma organização de caráter privado podem, mediante a disputa de editais, realizar ações delegadas a elas pelo Estado dando ensejo a um emaranhado de atribuições públicas e privadas. Nessa configuração, por exemplo, as políticas culturais ficam a cargo de interesses privados por meio de abonos fiscais, o que pode resultar em clientelismo e paternalismo dos/as beneficiados/ as pela ação estatal em relação à organização privada (Lautier, 2014). Assim, o direcionamento e financiamentos públicos, ao serem destinados a organizações privadas fazem com que os "alvos" da política pública sejam segmentados, de tal forma que não é um contingente populacional beneficiado pela política de Estado, mas um grupo circunscrito.

No Ponto de Cultura em questão, a motivação inicial para sua implementação partiu de pessoas ligadas à militância em movimentos sociais, em especial, de um militante de software livre filiado ao Partido dos Trabalhadores que tinha uma parceria com uma OSCIP que atuava na região do bairro Cristal de Porto Alegre. A OSCIP, por sua vez, estava sob responsabilidade de uma ex-vereadora pelo Partido dos Trabalhadores e associada a entidades de base como o Levante Popular da Juventude. Em 2005, após negociações entre esse militante e a OSCIP, foi escrito e enviado um projeto de Ponto de Cultura - o qual, após ser contemplado pelo MinC, foi apresentado para a Associação de Moradores do bairro. Esses, em caráter consultivo, aprovaram a ideia. Assim, o Ponto de Cultura passou a existir como um dos núcleos da OSCIP; essa realizou articulações com o Sindicato dos Trabalhadores do Judiciário Federal (Sintrajufe) cuja sede estava ociosa para ser o local onde hoje funciona o Ponto de Cultura.

Em 2007, quando da abertura oficial do local, o nome do Ponto de Cultura passou a ser Quilombo do Sopapo devido aos seus padrinhos: a Bataclã F.C. (banda de samba rock, nascida na periferia), Mestre Griô Giba Giba (músico) e Mestre Griô Baptista (artesão que construía Tambores de Sopapo) com o intuito de celebrar a cultura negra, tanto pela referência aos locais de resistência à escravidão - os Quilombos - quanto ao Tambor originário do território do extremo sul do Brasil, o 
Sopapo. Embora a referência à cultura negra seja apresentada como motor principal para a implementação do Ponto de Cultura pela coordenação do local consoante às diretrizes da Política Nacional Cultura Viva, nem sempre essa motivação era passível de ser percebida no tocante das atividades desenvolvidas.

No início do desenvolvimento de suas atividades, o Ponto de Cultura contou com projetos sendo realizados por coordenadores e/ou pessoas ligadas a movimentos sociais que possuíam projetos anteriores aprovados; isso ocorreu, pois o repasse financeiro do Ministério da Cultura apenas foi efetivado após a assinatura do convênio entre a OSCIP e o ministério - o que aconteceu apenas na metade de 2006. O atraso nos repasses financeiros, seguem na gestão atual do MinC (Ministro Sérgio Sá Leitão, 2017-atual) e são evidenciados na carta entregue pelos(as) representantes do Fórum de Secretários e Dirigentes Estaduais de Cultura (Ceará, 2017). Os repasses financeiros ao Ponto de Cultura em questão eram intermitentes, e as atividades ali desenvolvidas não necessariamente foram alinhadas aos pressupostos dos editais disputados - o que gerou um descompasso entre as promessas do Ponto de Cultura e o que efetivamente era possível de ser executado.

Esse descompasso em relação à apresentação do Ponto de Cultura como local de valorização da cultura negra e as atividades desenvolvidas (como de oficinas de vídeo ou empreendedorismo) geraram conflitos junto aos/as participantes do Ponto de Cultura e seus/as gestores/as, indicando também um uso do ambiente para fins não declarados abertamente pela coordenação e OSCIP. Um desdobramento desse descompasso entre a concepção e potencialidade do Ponto de Cultura no nível das diretrizes do Programa Cultura Viva e sua implementação pode ser visualizada na seleção dos/as participantes a integrarem o quadro funcional do local. No período de 2005-2007 a coordenação do Ponto de Cultura foi escolhida com base em conhecidos/as com ligação junto à OSCIP; pessoas ligadas a movimentos de militância (em especial, nas áreas de habitação, direito à cidade, comunicação); militantes de organizações como o Levante Popular da Juventude; e pessoas que chegaram ao local devido a parcerias do Ponto de Cultura com Escolas da região. Apenas na metade de 2007 foi realizada a seleção de participantes cuja residência fosse no bairro onde o Ponto de Cultura se encontrava; salienta-se que a seleção foi influenciada pela ligação das pessoas selecionadas com ex-coordenadores/as do local e por marcadores como gênero e raça - em um viés não estranho ao uso propagandístico dessas pautas pelo Ponto de Cultura.

Nesse particular, os/as participantes comentaram que ter ligação com o partido-político do militante de software livre, ser militante de movimentos sociais e ter conhecidos/as na OSCIP auxiliava na escolha para cargos de coordenação; quanto aos aspectos como gênero e raça, uma participante refere que foi escolhida porque haveria um "coordenador e tinha que ter outra mulher na casa, porque só iam ficar homens" e que na hora de serem escolhidos participantes do Ponto, havia uma escolha para ser integrante do quadro do Ponto de Cultura que era pautada por aspectos raciais: "Por que o Ponto de Cultura segue uma política e ela [ex-candidata] acha que não escolheram ela porque ela é branca". Essas escolhas, entretanto, aparentavam ter orientação voltada a propaganda da OSCIP via Ponto de Cultura, posto que não havia atividades desenvolvidas no espaço onde questões envolvendo gênero e raça fossem debatidos, nem esses/as participantes figuravam em cargos de coordenação e representação do Ponto de Cultura em conferências, fóruns ou congressos.

Visto que a implementação do local ocorreu alheio a um desejo prévio da comunidade, esse movimento suscita inicialmente algumas questões. Por um lado, a existência do Ponto de Cultura é vista como potente pelos/as jovens que frequentam o local, de tal forma que sua implementação sem o desejo da comunidade poderia ser compreendida como benéfica. Contudo, salienta-se: no período da realização da pesquisa não houve qualquer fiscalização por parte de algum/a representante do MinC no Ponto de Cultura, de tal forma que a avaliação das atividades do projeto ficava a cargo da OSCIP responsável, a qual enviava relatórios para o MinC periodicamente.

Por outro, cabe analisar a forma como esse espaço é implementado visto que não surge como um desejo da comunidade, mas parecer ter sido imposta a ela. Tanto a imposição quanto os possíveis benefícios podem ser compreendidos como uma ação de um ator externo com vistas a socorrer uma comunidade que necessita de auxílio; de qualquer forma, pressupõe-se que há alguém (em nosso caso, a comunidade) que comporta uma dimensão de passividade ou de "necessidade de favor". Nesse contexto, se é verdade que essa forma de gerenciamento do Ponto de Cultura 
em questão não é generalizável para todos os Pontos de Cultura no território brasileiro, também resulta ser discutível deixar a gestão de recursos financeiros de origem pública sob a ação de atores sociais privados sem a devida fiscalização desses mesmos recursos. Uma vez que essas ações são possibilitadas mediante uma política pública, essa forma de relação pode indicar como as comunidades periféricas brasileiras se tornam inteligíveis junto ao poder público.

Em suas considerações em relação às formas de ação política, Rancière $(2007,2011)$ argumenta que a pressuposição de incapacidade de alguns atores sociais no tocante a compreensão de sua condição social figura como um obstáculo quanto às possibilidades de emancipação social. Nesse sentido, tanto as ações por parte do Estado, quanto às perpetradas pela iniciativa privada podem figurar como um entrave quando não requeridas pelos atores sociais as quais essas são dirigidas; em especial, pode figurar nessa relação uma noção de incompetência por parte desses atores quanto aos rumos de suas ações e de suas próprias necessidades. Essa maneira de conceber os atores sociais, bem como sua forma de ação política é orientada pelo que o autor conceitua por uma lógica policial de partilha do sensível (Rancière, 2009). A lógica policial se caracteriza pela manutenção e regulação hierárquica entre os atores sociais, orientando-se por noções de competência e função quanto à execução de atividades, coordenação e resolução de conflitos e/ou direcionamento dos negócios comuns a uma comunidade (Rancière, 2009).

O processo de implementação do Ponto de Cultura no bairro analisado passa a impressão de que a comunidade possa ter sido utilizada como subsídio do Estado à OSCIP, porquanto a comunidade, nesse caso, figura como um objeto cujo valor para a OSCIP parece associado à propaganda e marketing. Segundo um/a participante: "nós temos uma gurizada da periferia [...] meio que eles se usam por terem contato com meio popular, entende? Isso abre mais portas". Essa "abertura de portas", uma vez que se torna possível por intermédio de uma ação estatal sob uma racionalidade neoliberal parece deixar a política cultural brasileira em uma situação delicada: simultaneamente, figura como um reconhecimento e legitimação da atividade cultural das comunidades periféricas delegando a elas representatividade e autoridade no tocante a produção cultural; e dá ensejo a utilização dessas mesmas comunidades em prol de interesses privados. Essa configu- ração, na qual a lógica policial permeia tanto a ação estatal, quanto a iniciativa privada, apresenta desdobramentos no cotidiano do Ponto de Cultura, em especial junto à trajetória de vida dos/as participantes e das relações laborais no local.

\section{Trajetórias de vida e divisão do trabalho}

As relações entre as trajetórias laborais e de vida dos/as participantes e a organização do trabalho desenvolvido no Ponto de Cultura estão associadas com a concepção que se tem de Ponto de Cultura e a concepção de sujeito ao qual essa política cultural se orienta. Nesse sentido, ocorrem diferentes negociações entre a OSCIP, os/as trabalhadores/as do Ponto de Cultura e as premissas sob as quais as políticas culturais brasileiras se assentam. Transversal aos/as trabalhadores/as do Ponto de Cultura se encontram trajetórias de vida marcadas por trabalhos informais e/ou desemprego, os quais são mantidos e regulados pelo Ponto de Cultura; não só, uma vez implementado o local, as funções a serem desenvolvidas, cargos a serem ocupados, propostas de oficinas, projetos e cursos não figuram como um ponto pacífico de discussão - apresentando conflitos com pautas de militância e trabalho no local.

As associações entre as políticas culturais brasileiras e a concepção de sujeito ao qual elas se orientam apontam para uma gama de usos e de compreensões em relação à cultura, arte, comunidade e direitos. Dessa forma, a formulação das políticas públicas culturais e as formas como elas são efetivadas pode indicar de que maneira os significados de "cultura", "arte" e os compromissos com aspectos relativos à militância e trabalho são operacionalizados junto ao contexto de monetização das políticas públicas (Feltran, 2014). Nesse particular, a monetização das políticas públicas implica em um atravessamento da racionalidade econômica neoliberal junto ao Estado brasileiro, o qual passa a conceber suas ações a partir do par investimento/retorno - resultando em práticas e contingentes populacionais "rentáveis" aos quais valeria o "investimento".

Essa sobrecodificação das atribuições públicas pela iniciativa privada dá margem às discussões referentes à produção de subjetividade capitalística teorizada por Guattari e Rolnik (1986) no que se refere às formas que o capitalismo pode assumir para além do âmbito da economia. Nesse sentido, a lógica econômica neoliberal figura em um campo jurídico no qual 
as ações e políticas de Estado são formuladas tendo como orientação uma concepção de sujeito cujas lógicas de competição, cálculos de rendimento/investimento e a capacidade de avaliar condições e aproveitar oportunidades aponta para um sujeito empreendedor de si (Magalhães, 2015).

Dessa maneira, a utilização de pautas como valorização da cultura negra, equidade racial e de gênero pela OSCIP passam a ser compreendidas como um investimento cuja rentabilidade seja lucrativa - o que implica em despolitização dessas pautas e usos das mesmas que contribuem para a não garantia de direitos sociais e manutenção da desigualdade social. Essas questões impactam, também, na rotina das pessoas que trabalham no Ponto de Cultura, podendo ser associadas a suas trajetórias de vida e a forma como o trabalho no local é organizado.

No Ponto de Cultura em questão ocorriam entre os/as trabalhadores/as cujos cargos não eram de coordenação discussões em relação à função da OSCIP no local e as propostas dos Pontos de Cultura segundo as premissas legais do Programa Cultura Viva. Como uma das estratégias a serem desenvolvidas para "barrar" a presença da OSCIP no local, muitos/as dos/ as participantes referiam a necessidade de projetos sendo redigidos, enviados, aprovados e executados - o que gerava certo retorno financeiro, bem como agregava mais moradores/as da comunidade junto ao Ponto de Cultura.

Entretanto, quando em períodos de baixa submissão e execução de projetos a OSCIP socorria o Ponto de Cultura em suas demandas básicas, investindo, principalmente, nas oficinas de Economia Solidária. Contudo, esses investimentos e a presença da OSCIP junto às demandas básicas do local não eram suficientes para manter um alto fluxo de moradores/ as junto ao espaço, nem a manutenção de trabalhadores/as. Isso, pois o trabalho realizado no Ponto de Cultura não era executado via assinatura da Carteira de Trabalho e Previdência Social (CTPS), não se configurando, portanto, como um vínculo de trabalho formalizado. Dessa forma, visto que nem os cargos de coordenação são formalizados, por vezes o atraso no repasse financeiro dos projetos aprovados gerava dificuldades aos/as trabalhadores/as, visto que necessitavam de renda para suprir suas demandas cotidia- nas. Nesses momentos, os/as participantes referem que a OSCIP disponibilizava "do nada" bolsas-auxílio de $R \$ 450,00$ ou $R \$ 800,00$ como forma de manutenção da equipe mínima de trabalhadores/as. Por vezes, os/ as participantes da pesquisa referiam apresentar relativa desconfiança quanto aos trâmites para obtenção das bolsas-auxílio. Nesse particular, o baixo valor das bolsas-auxílio e seu surgimento em momentos delicados pode ser explicado, segundo um/a participante, por estratégias de captação de recursos ilícitas:

Essa grana é assim ó. Eles repassam o dinheiro pra N., a jornalista aquela que estava ali na reunião. Eu não sei o valor que repassam pra ela, mas ela me repassa isso $[\mathrm{R} \$ 500,00]$. Que nem ela falou ali na reunião que ela é minha laranja. Ela falou isso! (D. trabalhador/a)

Essa forma de captação e manejo de recursos provenientes de fundos públicos e desviados de seus destinos legais pode ser compreendida como uma das consequências do uso de dinheiro público destinado a organizações privadas via disputa de editais. Adicionam-se, ainda, as potencialidades de abono fiscal decorrentes de atividades prestadas por essas mesmas organizações justificadas como empreendimentos artístico-culturais. Nesse sentido, as considerações e relações delicadas entre a política cultural e políticas de saúde na cidade de São Paulo, conforme apresentadas por Rizek $(2013)^{1}$, indicam que há necessidade de uma maior discussão em relação aos usos que as políticas culturais brasileiras vem adquirindo. Em especial, na manutenção e regulação de contingentes populacionais com trajetórias de trabalho informal, os quais por vezes são mantidos pelas políticas culturais brasileiras.

Figura, nesse sentido, um conflito recorrente no Ponto de Cultura: as ações de militância e a geração de renda necessária para a permanência dos/as trabalhadores/as do local. A partir de apontamentos pessoais registrados no diário de campo percebe-se que ainda que ações de militância fossem importantes, essas não geram retorno financeiro àqueles/as que as realizam. Dessa forma, as situações de trabalho informal se mantém pelo Ponto de Cultura por uma dupla articulação: do Programa Cultura Viva, pela viabili-

\footnotetext{
${ }^{1}$ Em seus trabalhos, a autora comenta sobre a utilização de fundos públicos das políticas culturais sendo utilizadas por empresas privadas na construção de postos de saúde, hospitais e faculdades de Medicina controladas, em alguns casos, por instituições religiosas e/ ou empreiteiras.
} 
zação dos Pontos de Cultura por meio da disputa de editais e não-obrigatoriedade da Carteira de Trabalho para a execução dos projetos do local; e pelas OSCIP, visto que os Pontos passam a ser uma extensão ou núcleo dessas.

\section{Militância}

A militância figura associada ao Ponto de Cultura, segundo os/as participantes, como uma das atividades da OSCIP e do Levante Popular da Juventude. Esses utilizavam o Ponto como local para a formação de militantes, sendo poucas as situações onde a militância não era conflitante com a rotina e cotidiano do Ponto de Cultura. Nesse sentido, por vezes há compreensões discrepantes em relação ao funcionamento e à concepção relativos ao uso do local: se por um lado há a compreensão de alguns/as dos/as participantes de que o Ponto de Cultura seria um espaço para formação de militantes, por outro há participantes que compreendem a atuação do Ponto circunscrita à produção cultural. Ainda que nessa questão não haja ponto pacífico, é interessante que independente da formação de militantes e da produção cultural realizada por agentes periféricos, há uma forma de relação com o sensível comum a ambos: o consenso (Rancière, 2011).

A utilização do Ponto de Cultura como um instrumento de captação e formação de futuros militantes foi comentada pelos/as participantes devido a conflitos que ocorriam em nível de coordenação e de relações do Ponto de Cultura, OSCIP e outras organizações parceiras. Pelos/as participantes, a utilização do local para formação de futuros militantes justificava o socorro da OSCIP às demandas básicas do Ponto de Cultura. Assim, segundo o/a participante C. ao mesmo tempo em que "a OSCIP fazia [...] um trabalho de base na moita" a coordenação "aparece com suas formações, ninguém nos pergunta se são essas formações que a gente quer. Por isso aquele dia eu perguntei: 'qual é nosso projeto aqui enquanto Ponto de Cultura? O que a gente quer alcançar?'”. É significativo, nesse sentido, que durante o planejamento das pautas de reunião para futuras ações do Ponto de Cultura alguns/mas militantes associados/as ao Levante Popular da Juventude tenham comentado entre si que embora não soubessem o significado do projeto do Ponto de Cultura interpretavam sua presença no local como importante de alguma maneira (notação $X-21$ de Julho de 2013 - diário de campo do pesquisador). Nesse particular, por parte dos/as coordenadores/as não havia distinção entre a atividade militante e produção cultural, embora para alguns/as trabalhadores/as o Ponto de Cultura figurasse como um espaço para formação de multiplicadores de cultura, como expressa D. trabalhador/a do Ponto de Cultura: "o objetivo do Ponto de Cultura é alcançar outros jovens que a gente não conseguiu ainda para estar aqui dentro do Ponto, não para formar militante".

Entretanto, independente das visões e circunscrições realizadas ao Ponto de Cultura, é transversal a ambas um modo de relação consensual (Rancière, 2011) que articula tanto a experiência política, quanto a produção cultural realizada - levando a questionamentos às possibilidades de emancipação social. Em seus textos, Rancière (2007) comenta sobre dois diferentes significados atribuídos à ideia de emancipação: emancipação enquanto um processo a ser atingido pela comunidade e emancipação como uma ruptura com uma maneira de relação com o sensível. Se a primeira noção de emancipação a pressupõe mediante o reconhecimento, das minorias, de seu estado de submissão e ilusão, a segunda a compreende como uma reorganização de construção da realidade, caracterizando o que o autor conceitua por dissenso (Rancière, 2007).

Uma forma de relação com o sensível dissensual implicaria em uma partilha do sensivel (Rancière, 2009) na qual se podem redistribuir as capacidades, competências e funções de maneira não naturalizada e/ou identitária - dando ensejo à construção de instâncias de enunciação não previstas pela partilha consensual (Rancière, 2011). Por consenso, o autor compreende não um estado de comum acordo, necessariamente, mas mais especificamente uma maneira de sentir o sensível da mesma forma. Uma comunidade consensual, então, ocorreria por uma experiência comum mediada segundo diferenças sensíveis entre os atores sociais, nas quais as possibilidades de dissidência e de construção de realidade estariam condicionadas segundo lógicas de hierarquia e competência (Rancière, 2011). Por conta disso, há uma articulação entre noções de emancipação e relações com o sensível que podem englobar conflitos e acordos que não implicam em uma ruptura ou mudança social dos atores envolvidos.

As ações de militância empreendidas pelos/as participantes tinham como orientação o envolvimento deles/as com partidos políticos e ações de militância em causas sociais, majoritariamente. No Ponto de Cultura em questão, essas figuravam 
como lutas por habitação e direito à cidade ou outra causa social militada pelo Partido dos Trabalhadores, ou pelo Levante Popular da Juventude. A criação do Ponto de Cultura, uma vez que é compreendida por coordenadores/as e por alguns/as membros/as da OSCIP como importante para a comunidade indicam uma noção de emancipação orientada por uma lógica policial (Rancière, 2007), posto que os/as moradores/ as da comunidade não tinham suas demandas ou necessidades levadas em consideração. A lógica policial se faz presente, portanto, tanto pela distribuição e manutenção hierárquica de funções (coordenadores, presidentes, secretários), quanto pelos temas eleitos pelos/as coordenadores/as (habitação, lutas anticapitalismo). De qualquer forma, indicam que existem atores sociais que necessitam de orientação para uma emancipação que se efetiva à custa de ser indefinidamente adiada.

Em contraponto a essa noção de emancipação, Rancière comenta uma lógica de emancipação a partir de uma "hipótese disparatada. Consideremos que os incapacitados são capazes e que não haja segredo [...] que os mantém ignorantes de sua condição" (Rancière, 2007, p. 102). Isso implica, pois, a possibilidade de atores sociais compreendidos como incapazes para o desempenho de algumas atividades sejam capazes de realizá-las, indicando a necessidade de se repensar o lugar da militância e seus procedimentos de ação. No Ponto de Cultura, para além dos planos e estratégias de ação da OSCIP, dos/as participantes engajados/as em ações de militância e dos/as trabalhadores/as do local, a existência de um espaço como o Ponto figurou como uma ação que propicia a possibilidade de cenas de dissensão (Rancière, 2007).

Nesse sentido, o diálogo abaixo servirá como ponto de partida para as considerações a seguir:

$\mathrm{E}^{2}$ : $\mathrm{E}$ tu falou que falta um propósito pro ponto de cultura, pra que serve o ponto de cultura afinal? Esse ponto de cultura.

P: O ponto de cultura serve pra mostrar cultura. Tipo a cultura popular ou outras coisas que a gurizada não tem acesso e que depois de um tempo a gurizada possa estar construindo.

E: Mas pra que serve isso? Por que as pessoas precisam conhecer esse tipo de cultura?

P: Porque as pessoas só conhecem uma.
Ao ser afirmado que as pessoas conhecem só um tipo de cultura, significa que comumente se sente e se concebe "cultura" por uma forma específica de relacionamento com o sensível, uma maneira consensual de produção cultural e uma comunidade política a qual essa se destina (Rancière, 2011). Quando, a partir do Ponto de Cultura, se podem construir diferentes culturas há a possibilidade de se erigir uma maneira de relação dissensual, em entre outras palavras, outra relação sensível e outra comunidade política possível. Como exemplo, houve no Ponto de Cultura durante o período de realização da pesquisa o lançamento de um livro intitulado "Imagens Faladas" (Seidl, 2010).

Esse livro foi criado a partir do testemunho de moradores/as da comunidade e reunido juntamente com fotografias tiradas pelos/as participantes de pesquisa, resultando em um registro da história e memória da comunidade permeado pelas fotografias e trechos transcritos. No "Imagens Faladas" (Seidl, 2010) as fotografias e os trechos selecionados das narrativas dos/as moradores/as orientam uma forma de percepção e relação sensível segundo uma determinada ordem de relacionamento entre o que se diz e o que se vê. Esse ordenamento, afeito ao pensamento de Arte identificada no Regime Representativo, presume uma supremacia da Palavra à Imagem, na qual a palavra opera uma dupla retenção: retenção do poder da palavra em função do que se vê e uma retenção da própria potência do visível (Rancière, 2009). Essa dupla retenção operada pelo regime representativo conceitua o que o autor nomeia por palavra viva: uma forma de escrita cuja palavra institui um regime de visibilidade em relação à imagem e manifesta sentimentos e vontades que estariam contidos no visível. Quando uma produção em Arte tem como pressuposto essa forma de pensamento ela institui uma maneira de relação sensível que assegura, via uma noção de mímese, uma configuração de olhar e sentir - ou seja, um consenso (Rancière, 2009, 2011).

Dos possíveis cenários de resolução da problemática estética da arte, a promessa de uma comunidade política dissensual pode figurar confinada na Obra de Arte, que pode ser concebida com as propriedades do regime estético e que passa a existir como materialização de uma passagem da vida à obra (Rancière, 2011). Nesse sentido, tem-se uma comunidade que

\footnotetext{
${ }^{2}$ E: entrevistador. P: participante.
} 
se encontra contida na Obra de Arte, onde há identidade plena entre os contrários e sua historicidade; equivale dizer: a comunidade dissensual se esgota em uma Obra de Arte que se perde em sua potência. O "Imagens Faladas" (Seidl, 2010) ao mesmo tempo em que dá ensejo a uma ruptura com a lógica policial ao apresentar atores sociais periféricos que criam Arte e Cultura, retém o dissenso na Obra. Essa passa a ser expressão de um paradoxo de um modo de vida coletivo: ela é expressão de um modo de vida na medida em que exprime o que falta na vida comunitária, ou seja: supressão de hierarquias e restrições ao que se considera Arte e a quem tem capacidade de a criar. E não é na medida em que falha nessa expressão, passando a exprimir sua limitação: como a Obra encerra uma comunidade, essa passa a ser cultuada, dissociando-se os/as criadores/as da obra, sua destinação e sua promessa de vida comunitária.

\section{Considerações finais}

As políticas culturais brasileiras atuais indicam que sua formulação, bem como a concepção de sujeito ao qual se orientam estão, em certa medida acertadas, o que não significa que estejam pautadas por um processo de supressão de desigualdades sociais e emancipação social. Nesse particular, a concepção de sujeito neoliberal ao qual ela se orienta tem como reflexo, por vezes, a apropriação de fundos públicos para levantamento de lucros privados, figurando a utilização despolitizada de questões como gênero e raça. Com isso, a desigualdade social é mantida por meio da regulação de contingentes populacionais através de trabalhos informais indicando que o reconhecimento e inserção das comunidades periféricas ocorre quando essas passam a ser "rentáveis" de alguma forma: seja para financiamento de empreendimentos privados pelas OSCIP via fundos públicos, seja como formação de militantes para partidos-políticos.

A existência dos Pontos de Cultura, nesse sentido, ainda que permeadas por um viés marcadamente mercadológico, permitem aos atores sociais que outrora não tinham um reconhecimento oficial de cultura passem a construir "oficialmente" uma noção de cultura brasileira. Essa possibilidade traz consigo a potência de reorganização dos regimes de sensibilidade consensuais e a promessa de relações comunitárias dissensuais e políticas (Rancière, 2007). Contudo, cabe comentar que essa potência, por si só, não é suficiente para a ruptura dos modos de subjetivação policiais pautados pelo consenso, posto que esses se articulam e interpenetram de maneira insidiosa estando em constante processo de negociação, conflito e dissidência convivendo com formas políticas de existência. Dessa maneira, a promessa de comunidade futura propiciada pelas ações do Programa Nacional Cultura Viva convive com o reconhecimento do direito ao pleno exercício de cidadania, cuja via de expressão, ainda que ampla e diversa, pode se encontrar nas produções culturais e artísticas cotidianas de um livro de fotografias.

\section{Referências}

Brasil. (2005). Cultura viva. Recuperado de http://culturaviva.org.br/programa-cultura-viva/

Ceará. (2017). Secretaria da Cultura. Forum Nacional de Secretários e Dirigentes Estaduais de Cultura. Fortaleza: Secretaria da Cultura. Recuperado de http://www.secult.ce.gov.br/index.php/latest-news/46270-forum-nacional-de-secretarios-e-dirigentes-estaduais-de-cultura-divulga-carta-sobre-a-atual-situacao-do-ministerio-da-cultura

Feltran, G. (2014). O valor dos pobres: a aposta no dinheiro como mediação para o conflito social contemporâneo. Cadernos CRH/UFBA, 27(72), 495-512

Guattari, F, \& Rolnik, S. (1986). Micropolíticas: cartografias do desejo (4a ed.) Petrópolis, RJ: Vozes.

Lautier, B. (2014). O governo moral dos pobres e a despolitização das políticas públicas na América Latina. Cadernos CRH/UFBA, 27(72), 463-477.

Lei No 13.018, de 22 de julho de 2014. Institui a Política Nacional de Cultura Viva e dá outras providências. Diário Oficial da União, 23 jul. 2014.

Magalhães, F. N. C. (2015). O neoliberalismo e a produção do espaço na metrópole: subjetividades, insurgências e redes de economia política da urbanização contemporânea (Tese). Instituto de Geociências da Universidade Federal de Minas Gerais, Belo Horizonte, MG, Brasil. 
Peirano, M. (2014). Etnografia não é método. Horizontes Antropológicos, 20(42), 377-391. http://dx.doi.org/10.1590/ s0104-71832014000200015

Rancière, J. (2007). As desventuras do pensamento crítico. In: Rui Cardoso (Org.), Crítica do pensamento contemporâneo: Giorgio Agamben, Giacomo Marramao, Jacques Rancière, Peter Sloterdijk (pp. 75-99). São Paulo, SP: Fundação Serralves

Rancière, J. (2009). O inconsciente estético. São Paulo: Editora 34.

Rancière, J. (2011). A comunidade estética. Revista Poiésis, (17), 169-187.

Rizek, C. A. (2013). Políticas sociais e políticas de cultura: territórios e privatizações cruzadas. Revista Brasileira de Estudos Urbanos e Regionais, 15(2), 199-201. https://doi.org/10.22296/2317-1529.2013v15n2p199

Seidl, E. (Org.). (2010). Imagens faladas: uma reportagem sobre a memória do Bairro Cristal. Cidade: Ed. do Autor.

Silva, R. H. A., \& Dutra, R. A. (2011). MINC: políticas de cultura? Cadernos PPG-AU UFBA, 10(n. esp.), 97-111.

Spink, M. J. P. (2007). Pesquisando no cotidiano: recuperando memórias de pesquisa em psicologia social. Psicologia \& Sociedade, 19(1), 7-14. https:// doi.org/10.1590/S0102-71822007000100002

UNESCO - Organização das Nações Unidas para a Educação, a Ciência e a Cultura. (2005). Convenção sobre a proteção e promoção da diversidade das expressões culturais. Paris: Organização das Nações Unidas.

\section{Adolfo Pizzinato}

Psicólogo e Mestre em Psicologia Social e da Personalidade pela (PUC-RS). Porto Alegre - RS. Brasil. Doutor em Psicologia pela Universitat Autònoma de Barcelona (Prêmio Extraordinário de Tese Universitat Autònoma de Barcelona 2007-2008). Professor Adjunto do Departamento de Psicologia do Desenvolvimento e da Personalidade da Universidade Federal do Rio Grande do Sul (UFRGS), Porto Alegre - RS. Brasil. Professor do Programa de Pós-Graduação em Psicologia e Coordenador da Residência Integrada em Saúde Mental Coletiva, da UFRGS.

E-mail: adolfopizzinato@hotmail.com

\section{Pedro de Castro Tedesco}

Graduação em Psicologia pela Pontificia Universidade Católica do Rio Grande do Sul e mestrando em Psicologia Social e Cultura pela Universidade Federal de Santa Catarina (UFSC).

E-mail: pedrocastro.tedesco@gmail.com

\section{João Pedro Cé}

Graduação e Mestrado em Psicologia pela Pontifícia Universidade Católica do Rio Grande do Sul (PUC-RS). Porto Alegre-RS. Brasil.

E-mail: joaopedroce@yahoo.com

Endereço para envio de correspondência

Rua Ramiro Barcelos, 2600 - Sala 104. CEP: 90035-003.

Porto Alegre - RS. Brasil.

Recebido 20/04/2017

Reformulado 09/10/2017

Aprovado 20/12/2017

Received 04/20/2017

Reformulated 10/09/2017

Approved 12/20/2017 
Psicologia: Ciência e Profissão Out/Dez. 2018 v. 38 n4, 636-648.

Recibido 20/04/2017

Reformulado 09/10/2017

Aceptado 20/12/2017

Como citar: Pizzinato, A., Castro-Tedesco, P., \& Cé, J. P. (2018). Comunidade Porvir: Emancipação social e configurações comunitárias em um ponto de cultura. Psicologia: Ciência e Profissão, 38(4), 636-648. https://doi.org/10.1590/1982-3703001312017

How to cite: Pizzinato, A., Castro-Tedesco, P., \& Cé, J. P. (2018). Possible communities: Social Emancipation and Communitarian Arrangements in a Ponto de Cultura. Psicologia: Ciência e Profissão, 38(4), 636-648. https://doi.org/10.1590/1982-3703001312017

Cómo citar: Pizzinato, A., Castro-Tedesco, P., \& Cé, J. P. (2018). Comunidad Porvenir: Emancipación social y configuraciones comunitarias en un punto de cultura. Psicologia: Ciência e Profissão, 38(4), 636-648. https://doi.org/10.1590/1982-3703001312017 